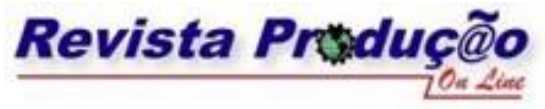

\title{
PERCEPÇÃO DO CONCEITO DE PLÁGIO ACADÊMICO ENTRE ALUNOS DE ENGENHARIA DE PRODUÇÃO E AÇÕES PARA SUA REDUÇÃO
}

\section{THE PERCEPTION OF ACADEMIC PLAGIARISM CONCEPT AMONG PRODUCTION ENGINEERING STUDENTS AND ACTIONS FOR ITS REDUCTION}

\author{
Rafael Garcia Barbastefano \\ Professor Adjunto \\ CEFET/RJ \\ Departamento de Engenharia de Produção \\ Av. Maracanã, 229, B1. E, 1o. andar. Rio de Janeiro, RJ. \\ Tel. 21-2566-3015, e-mail: rgb @ cefet-rj.br

\section{Cristina Gomes de Souza} \\ Professora Adjunta \\ CEFET/RJ \\ Departamento de Engenharia de Produção, Programa de Mestrado em Tecnologia \\ Av. Maracanã, 229, Bl. E, 1o. andar. Rio de Janeiro, RJ. \\ Tel. 21-2566-3015, e-mail: cgsouza@cefet-rj.br
}

\begin{abstract}
RESUMO
A preocupação com o plágio vem aumentando significativamente no meio acadêmico. Diversos artigos sobre o tema vêm sendo publicados em periódicos de diversas áreas. Entre as razões para tal prática são citados o desconhecimento de legislação, a facilidade de obtenção de trabalhos e a incapacidade de parafrasear por parte dos autores. O objetivo do artigo é apresentar os resultados de uma pesquisa sobre direitos autorais realizada junto aos alunos de um curso de Engenharia de Produção da Cidade do Rio de Janeiro, além de um conjunto de ações de combate ao uso indevido da propriedade intelectual. A pesquisa, baseada no envio de questionários pela Internet, apontou para o desconhecimento do assunto por parte do alunado e a utilização de fontes de pesquisa sem qualificação.
\end{abstract}

Palavras-chave: Plágio Acadêmico, Cybercheating, Internet. 
ISSN 1676 - 1901 / Edição especial/dezembro de 2007

Artigo selecionado dos anais - XXVII Encontro Nacional de Engenharia de Produção

\begin{abstract}
Academia has been concerned with plagiarism in last ten years. Literature has shown several works in many areas about this issue. These works cite as explanations for cybercheating: lack of knowledge about plagiarism and its legislation, easy obtention of academic material, and incacpacity of paraphrasing. The goal of this article is presenting the results of a survey about copyrights acomplished with Production Engineering students in Rio de Janeiro, and actions for curb academic dishonesty. This survey indicated lack of information about the subject, and the use of unqualified sources of information.
\end{abstract}

Key-words: Academic Plagiarism, Cybercheating, Internet.

\title{
1. INTRODUÇÃO
}

A Internet é saudada todos os dias como importante fonte de conhecimento e pesquisa para estudantes e pesquisadores, tanto pela quantidade de informações disponíveis, quanto pela facilidade de busca e acesso. Entretanto, a mesma Internet é vista como fonte de preocupação pela facilitação do plágio e da desonestidade acadêmica.

Tal preocupação não é nova. Connors, em 1996, no início da consolidação da WWW, já apontava como problema emergente o aparecimento de sites especializados em fornecer cópias de trabalhos acadêmicos. Nos últimos dez anos, o problema cresceu e alguns autores já afirmam que o problema do plágio hoje não encontra precedentes. Como diz Garschagen (2006) - "Plagiar nunca foi tão fácil e freqüente nas universidades brasileiras".

Algumas instituições, inclusive, já vêm discutindo e adotando regras mais rígidas, com estabelecimento de punições para alunos, professores e pesquisadores que pratiquem tais atos ilícitos. Podemos citar como exemplo muito recente, a expulsão, na China, de pesquisador que teria cometido fraude ao apresentar chip do fabricante Motorola como sendo de sua autoria (Scofield, 2007).

Independente do aspecto ético, qual seria o conhecimento dos alunos de graduação acerca dos Direitos Autorais? Até que ponto estão cientes das violações que estejam comentendo? Outros fatores são apontados na literatura como causa para o plágio acadêmico na era da Internet: facilidade de acesso à informação, falta de análise crítica em relação aos textos e dificuldades de parafrasear. 
Este trabalho se dedica a investigar o conhecimento a respeito de direito autoral junto a alunos de graduação de Engenharia de Produção do CEFET-RJ, com o objetivo de propor uma política de esclarecimento aos alunos e combate ao plágio. Através da aplicação de questionários, pretendeu-se verificar o nível de conhecimentos acerca da legislação, uso de citações, paráfrases e imagens.

A motivação para a realização da pesquisa foi decorrente da identificação de casos de plágio praticados por alunos, levando à reprovação de Projetos Finais. Além dos resultados da pesquisa, o trabalho apresenta uma breve revisão bibliográfica sobre o tema, bem como aspectos da legislação brasileira sobre Direitos Autorais.

\section{PLÁGIO EM TRABALHOS ACADÊMICOS}

A preocupação com os Direitos Autorais e com a propriedade intelectual não é nova. Entretanto, com o advento da Internet, o tema das suas violações veio à tona, com o aparecimento na literatura de uma série de trabalhos sobre o assunto desde 1996 com o trabalho de Connors.

Em diversas áreas do conhecimento, vemos artigos sobre o tema: Billic-Zulle et al. (2005) tratam do problema em estudantes de medicina; Cardoso (2004) em administração e Kock (1999) em ciência da computação. Estes são apenas alguns exemplos de publicações que têm aparecido com frequência em periódicos especializados.

A reprodução integral ou parcial de uma propriedade intelectual e ou artística, assumindo-se uma autoria que pertence a outrem, é denominada plágio. A palavra plágio tem sua origem no grego plágios, que significa oblíquo, assinar ou apresentar como seu (obra artística ou científica de outrem), imitar (trabalho alheio). Esta definição necessariamente convoca os conceitos de autenticidade e originalidade. (Hartman, 2006).

Os Direitos Autorais inserem-se no campo da chamada propriedade intelectual e visam garantir os direitos morais e patrimoniais do autor em relação à obra que criou. Assim sendo, cabe ao autor o direito exclusivo de utilizar, fruir e dispor da obra, seja ela literária, artística ou científica.

No caso do Brasil, os direitos autorais são regidos por legislação específica - Lei no. 9.610 de 19 de fevereiro de 1998. De acordo com a referida lei, a reprodução não autorizada 
de uma obra constitui-se em contrafação estando os infratores sujeitos às sanções civis e penais cabíveis. O assunto também é tratado no Código Penal em vigor, no Título que trata dos Crimes Contra a Propriedade Intelectual - artigo 184 - que traz o seguinte teor: Violar direito autoral: Pena - detenção, de 3 (três) meses a 1 (um) ano, ou multa.

Embora não seja permitida a reprodução parcial ou integral de uma obra sem prévia expressa autorização do autor, a lei diz que não constitui ofensa aos direitos autorais a citação de passagens de qualquer obra, para fins de estudo, crítica ou polêmica, desde que indicado o nome do autor e a origem da obra.

O mau uso de fontes nos trabalhos acadêmicos é estudado por diversos autores que apontam uma série de causas para o fenômeno como:

- Facilidade de acesso à informação - Gibelman et. al. (1999), Stebelman (1998) e Austin e Brown (1999) chamam a atenção para uma série de sítios na Internet que vendem trabalhos acadêmicos prontos, ou sob encomenda, com nomes sugestivos como CheatHouse (http://www.cheathouse.com) e Hotessays (http://www.hotessays.com). No Brasil, é famoso o site Zé Moleza (http://www.zemoleza.com.br) entre alunos de graduação.

- Falta de capacidade para parafrasear - Apesar de manuais de metodologia como Eco (1994, p. 128) ressaltarem as diferenças entre citações, paráfrases e plágio, Wood (2004) chama a atenção para o fato dos alunos não saberem elaborar redações "com as suas próprias palavras".

- Alunos dão pouco valor ao próprio trabalho - Wood (2004) afirma que os alunos não consideram seu trabalho como válido ou merecedor de proteção intelectual.

- Falta de análise crítica de trabalhos e confusão em relação à propriedade na Internet Um fenômeno interessante, ressaltado por Wood (2004) e estudado mais a fundo por Graham e Metaxas (2003), é verificar-se a falta de análise crítica de informação obtida através da Internet. Se está publicado na rede, então a informação é disponível, verdadeira e livre. A confusão em relação à propriedade intelectual na WWW também é apresentada por Garschagen (2006) como uma das causas do plágio.

- Incentivo ao plágio nos níveis fundamental e médio - Garschagen (2006) apresenta como uma das razões para a disseminação do uso indevido o seu estímulo nos níveis de 
ensino fundamental e médio. É comum considerar-se como "pesquisa", no ensino fundamental, o recorte e a colagem de figuras de jornais e revistas para elaboração de cartazes. Com a Internet, esse tipo de pesquisa fica facilitado.

- Facilidade de acesso a programas de tradução - Stebelman (1998) ressalta que não apenas a cópia de textos é um problema, mas a tradução também se configura em uso indevido. Este é um problema mais grave pela impossibilidade de rastreamento por ferramentas automáticas de busca. Pelo fato da maior parte das publicações em Engenharia serem em inglês, este fato é ainda mais grave para as universidades brasileiras.

- Desconhecimento de regulamentações - Austin \& Brown (1999) apontam como uma das causas para o plágio o desconhecimento das regras que delimitam o uso de citações e paráfrases. De uma maneira geral, o desconhecimento de regras e legislações facilita a sua transgressão.

\section{METODOLOGIA}

Utilizou-se como metodologia o envio de questionários do tipo survey para alunos de início (primeiro ano) e término (quinto ano) do curso de Engenharia de Produção do CEFETRJ. Foram enviados 157 questionários e 79 ( 50,3\%) ao longo do ano de 2007. As respostas coletadas via Internet, através de uma ferramenta denominada PhpSurveyor (http://phpsurveyor.org), que permite a automatização dos convites para preenchimento dos questionários, coleta e tabulação dos dados.

O questionário procurou verificar os seguintes pontos através de 18 perguntas, tanto de caráter aberto, quanto fechado:

- Conhecimento da legislação por parte dos alunos

- Uso devido e indevido de citações

- Fontes de pesquisa

- Uso de imagens 
Artigo selecionado dos anais - XXVII Encontro Nacional de Engenharia de Produção

\section{ANÁLISE DOS RESULTADOS}

As primeiras perguntas do questionário se referiam à identificação dos alunos. O quadro 1 apresenta o número de ingressantes e concluintes que participaram da pesquisa, além da distribuição por gênero. Foi perguntado também a forma de ingresso na instituição e a quase totalidade dos alunos (77) mencionou o vestibular.

\begin{tabular}{lccc}
\hline & F & M & Total \\
\hline Ingressantes & 20 & 19 & 39 \\
Concluintes & 19 & 21 & 40 \\
\hline Total & 39 & 40 & 79 \\
\hline
\end{tabular}

Quadro 1 - Perfil dos alunos, ingressantes ou concluintes e de acordo com o gênero.

Nas questões referentes ao conhecimento da legislação e ao uso de citações, foram perguntados se o plágio na Legislação Brasileira constitui-se em Crime, Contravenção ou Ofensa Civil. Perguntou-se qual seria o tamanho máximo permitido de uma paráfrase, bem como as condições nas quais a reprodução de obras intelectuais seja permitida e duas questões abertas sobre o conceito de plágio e domínio público. Os resultados se encontram na Figura 1:

De acordo com a Lei Brasileira, plágio é:

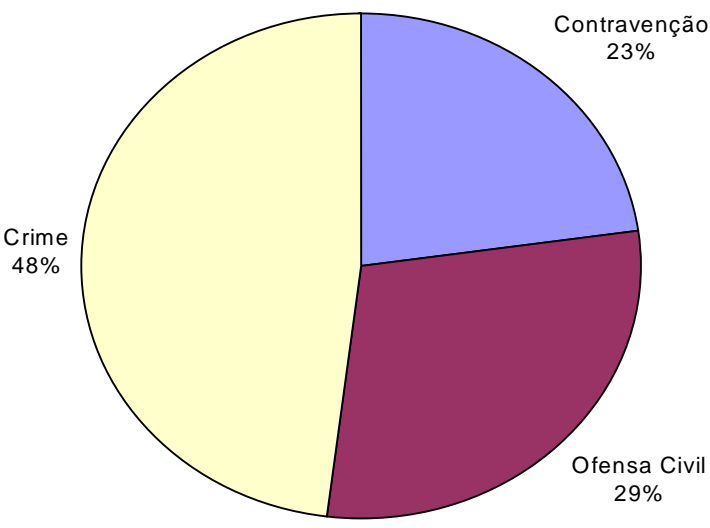

Figura 1 - Percentuais de resposta para o que significa plágio na Legislação Brasileira 


\section{Para você, qual deve ser o tamanho máximo de uma paráfrase, para que não haja violação de Direito Autoral?}

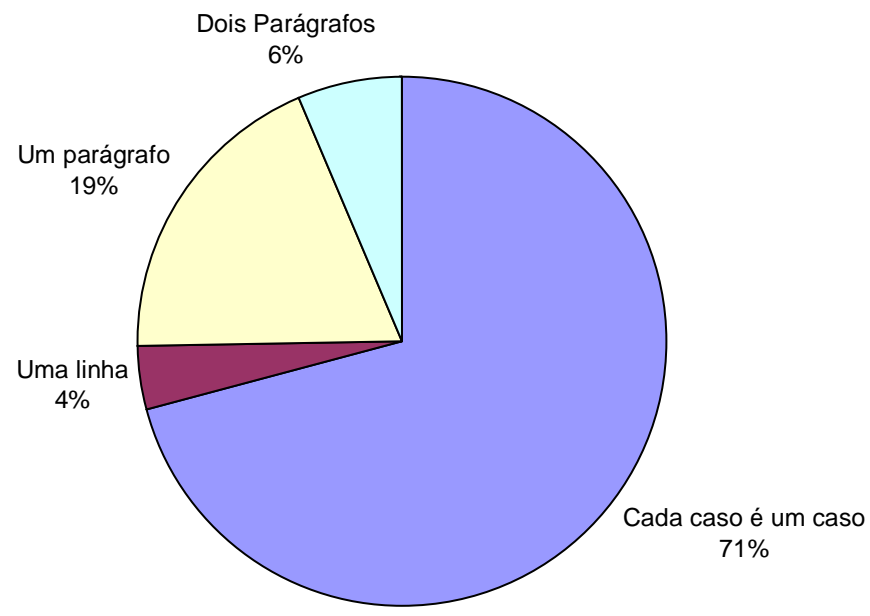

Figura 2 - Percentuais de resposta para o tamanho máximo de uma paráfrase.

Com relação à Figura 1, pode-se verificar que mais da metade dos alunos não considera que o plágio seja caracterizado como crime segundo a Legislação Brasileira. Isto indica que, para os mesmos, o plágio teria um status de "falta menor", confirmando o texto de Austin \& Brown (1999). Por outro lado, 66\% dos alunos indicou corretamente a opção "Cada caso é um caso" ao se referirem ao tamanho máximo de uma paráfrase (Figura 2, obs: foi indicado o conceito de paráfrase na pergunta do questionário).

Um resultado importante aparece no gráfico da Figura 3. Foi feita uma pergunta na qual o respondente deveria indicar quais seriam as situações nas quais seria possível realizar a reprodução de uma obra intelectual (com múltiplas respostas possíveis). Dentre as opções, apenas duas eram corretas: "Quando quem de direito autorize a reprodução" e "Quando a obra seja de domínio público". A segunda opção mais assinalada (superando uma das corretas) foi "Quando o autor seja devidamente referenciado". Tal resposta indica que, para os alunos, 
bastaria referenciar o autor de uma obra para que a mesma pudesse ser reproduzida.

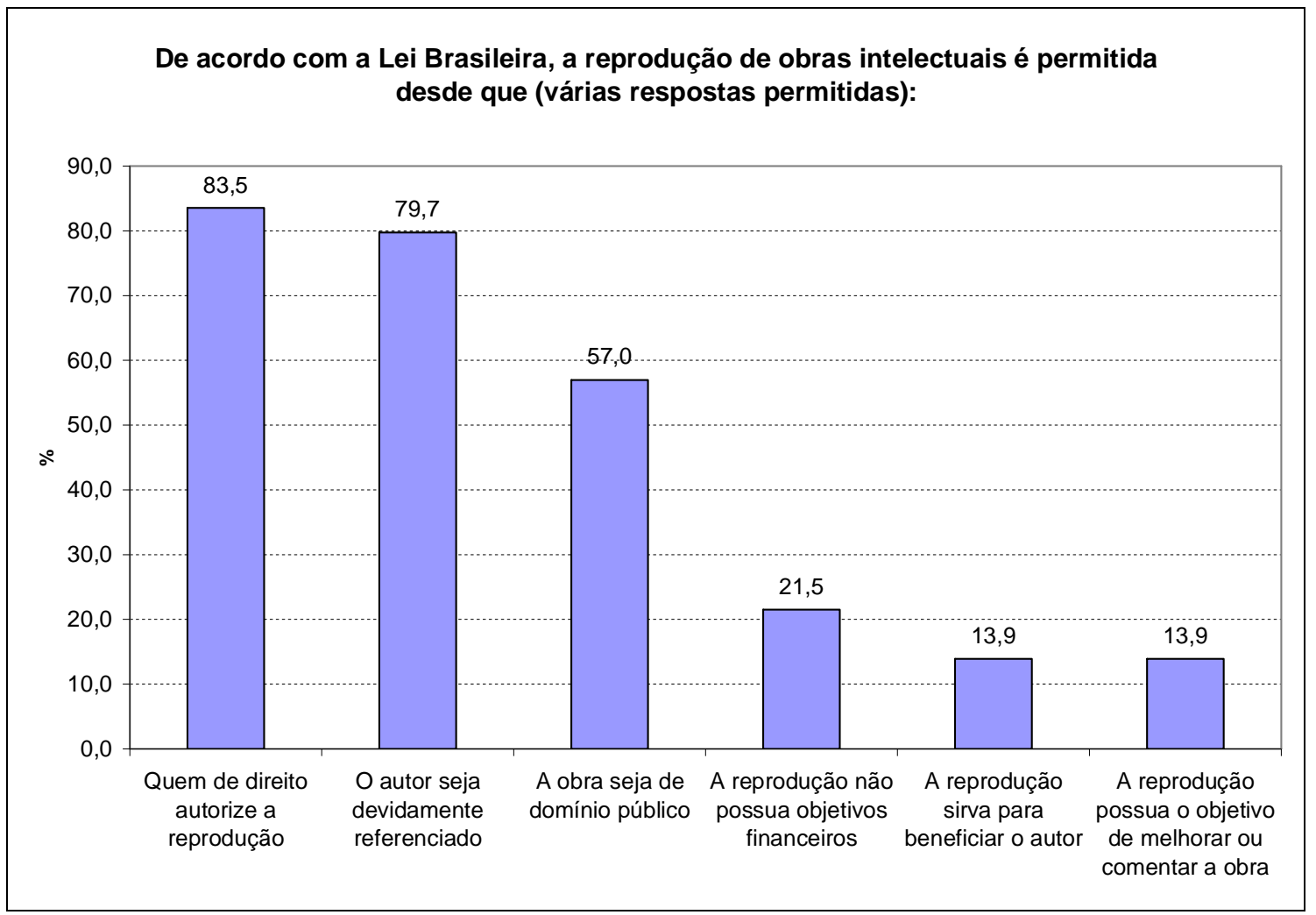

Figura 3 - Os percentuais de resposta para quais situações a reprodução de obras intelectuais é permitida

Quanto às questões abertas sobre plágio e domínio público, os alunos revelaram um conhecimento intuitivo sobre o primeiro conceito que se aproxima da definição legal, enquanto revelaram desconhecimento em relação ao segundo conceito, confundindo-o com acesso público ou de informação livre. Podem-se ver algumas respostas selecionadas no Quadro 2. Chega a ser irônico, mas é importante dizer que algumas respostas foram obtidas em sítios da Internet pelos respondentes. 


\begin{tabular}{|c|c|}
\hline O que você entende por plágio? & O que você entende por domínio público? \\
\hline $\begin{array}{l}\text { Ato de copiar abertamente algo de outrem sem sua devida } \\
\text { autorização. }\end{array}$ & $\begin{array}{l}\text { São obras q não tem autores definidos, são } \\
\text { posse da humanidade. }\end{array}$ \\
\hline $\begin{array}{l}\text { Significa roubar idéias ou trabalhos de outras pessoas, } \\
\text { apresantando como algo próprio }\end{array}$ & Algo notório, que está disponível a todos. \\
\hline $\begin{array}{l}\text { Copiar um trabalho ou obra de um autor sem mencionar o } \\
\text { mesmo, enganando o leitor que a obra é de sua autoria. }\end{array}$ & $\begin{array}{l}\text { Algo que você copiar e utilizar sem } \\
\text { problemas. }\end{array}$ \\
\hline $\begin{array}{l}\text { Utilizar de conhecimento desenvolvido por outros como se } \\
\text { fosse seu sem permissão do criador }\end{array}$ & $\begin{array}{l}\text { Concessão de acesso a todo e qualquer } \\
\text { público. }\end{array}$ \\
\hline $\begin{array}{l}\text { Plágio para mim seria tentar imitar algo que alguém já tenha } \\
\text { feito ou me apropriar de uma coisa que outra pessoa tenha } \\
\text { inventado ou feito dizendo que eu seria o autor. }\end{array}$ & Algo que é de livre acesso ao povo. \\
\hline $\begin{array}{l}\text { Plágio, na minha opinião, é uma situação na qual uma pessoa } \\
\text { "pega" algo feito por outra e diz que é seu, querendo tirar } \\
\text { algum benefício sobre isso. }\end{array}$ & Domínio Público é tudo aquilo do Governo. \\
\hline $\begin{array}{l}\text { Assinar uma obra ou parte dela sem identificar o autor } \\
\text { original. }\end{array}$ & $\begin{array}{l}\text { É algo que qualquer Cidadão tem o Direito } \\
\text { de Saber. }\end{array}$ \\
\hline
\end{tabular}

Quadro 2 - Respostas selecionadas de duas questões abertas sobre os conceitos de Plágio e Domínio Público

Em seguida, foram formuladas duas perguntas, apresentando duas paráfrases indevidas de um trecho do livro "Hora Final", de Martin Rees (Ed. Companhia das Letras). $\mathrm{Na}$ primeira paráfrase, o trecho omitia a fonte e usava as mesmas palavras do original com algumas trocas de posição. Na segunda paráfrase, havia uma cópia integral do trecho com citação. No entanto, a paráfrase não se encontrava em discurso indireto, tãopouco entre aspas, revelando uma citação indevida como mostra Eco (1994). Foi perguntado se cada paráfrase era válida ou não, pedindo justificativas em seguida. Os resultados se encontram na Figura 4: 
Artigo selecionado dos anais - XXVII Encontro Nacional de Engenharia de Produção

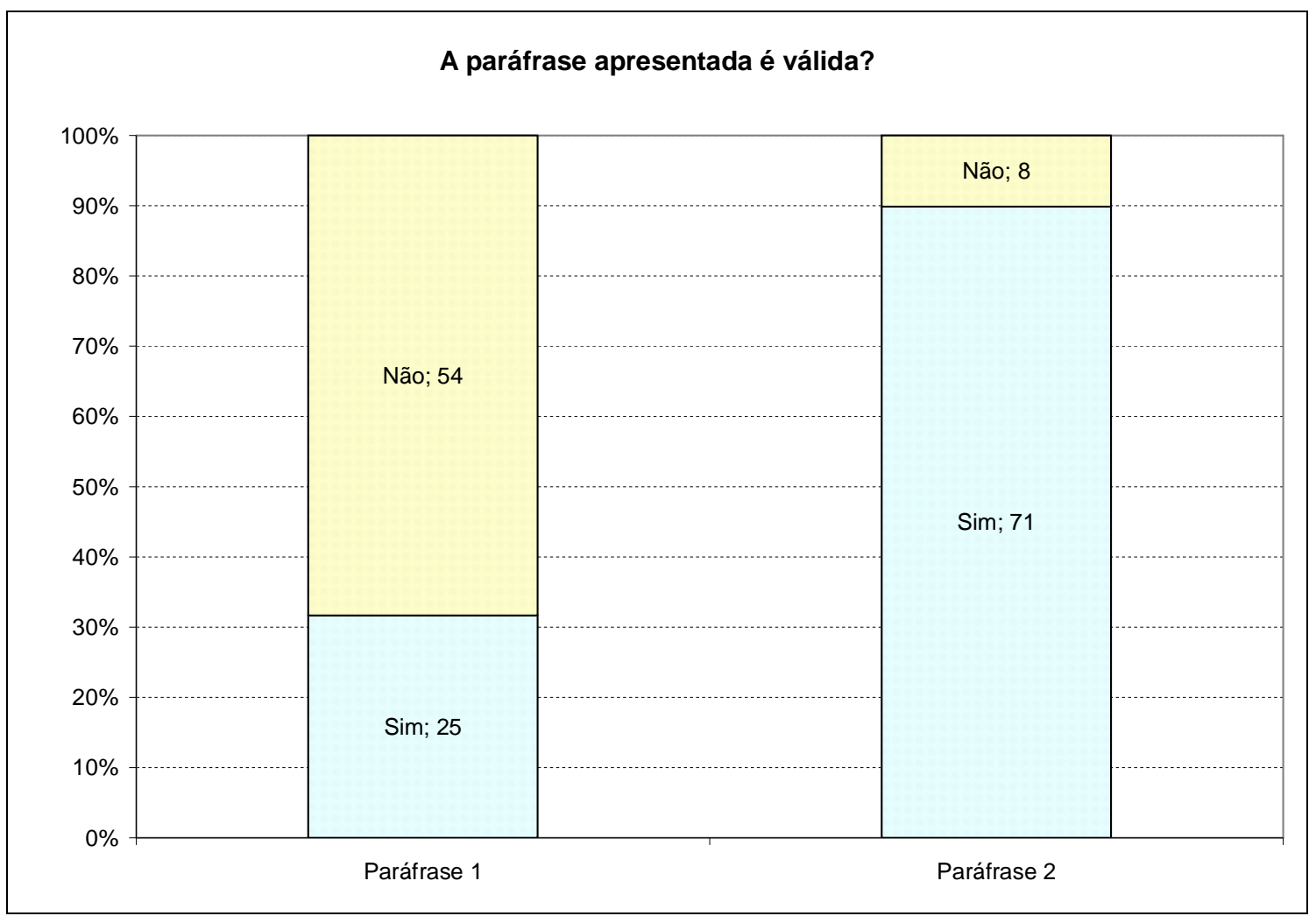

Figura 4 - Respostas obtidas em relação às paráfrases.

Os resultados corroboram a afirmação que a "reprodução é permitida desde que o autor seja referenciado" em questão anterior. Para os alunos que responderam corretamente a questão sobre a segunda paráfrase, a maioria indicou a necessidade de aspas.

Em seguida, foi solicitado que os alunos indicassem quais fontes de pesquisa são utilizadas nos trabalhos acadêmicos. Foram apresentadas diversas opções com possibilidade de múltiplas respostas, cujos percentuais se encontram na Figura 5. Os resultados indicam uma predileção por fontes sem revisão como a Internet através do Google e a Wikipedia. Bases de artigos e pré-prints como Scielo e Citeseer receberam muito poucos registros, bem como o site Zemoleza.com que diponibiliza trabalhos para cópia. Essa preferência possui problemas como a indicação de resultados incorretos ou procedimentos enviesados, como apontado por Graham e Metaxas (2003). 


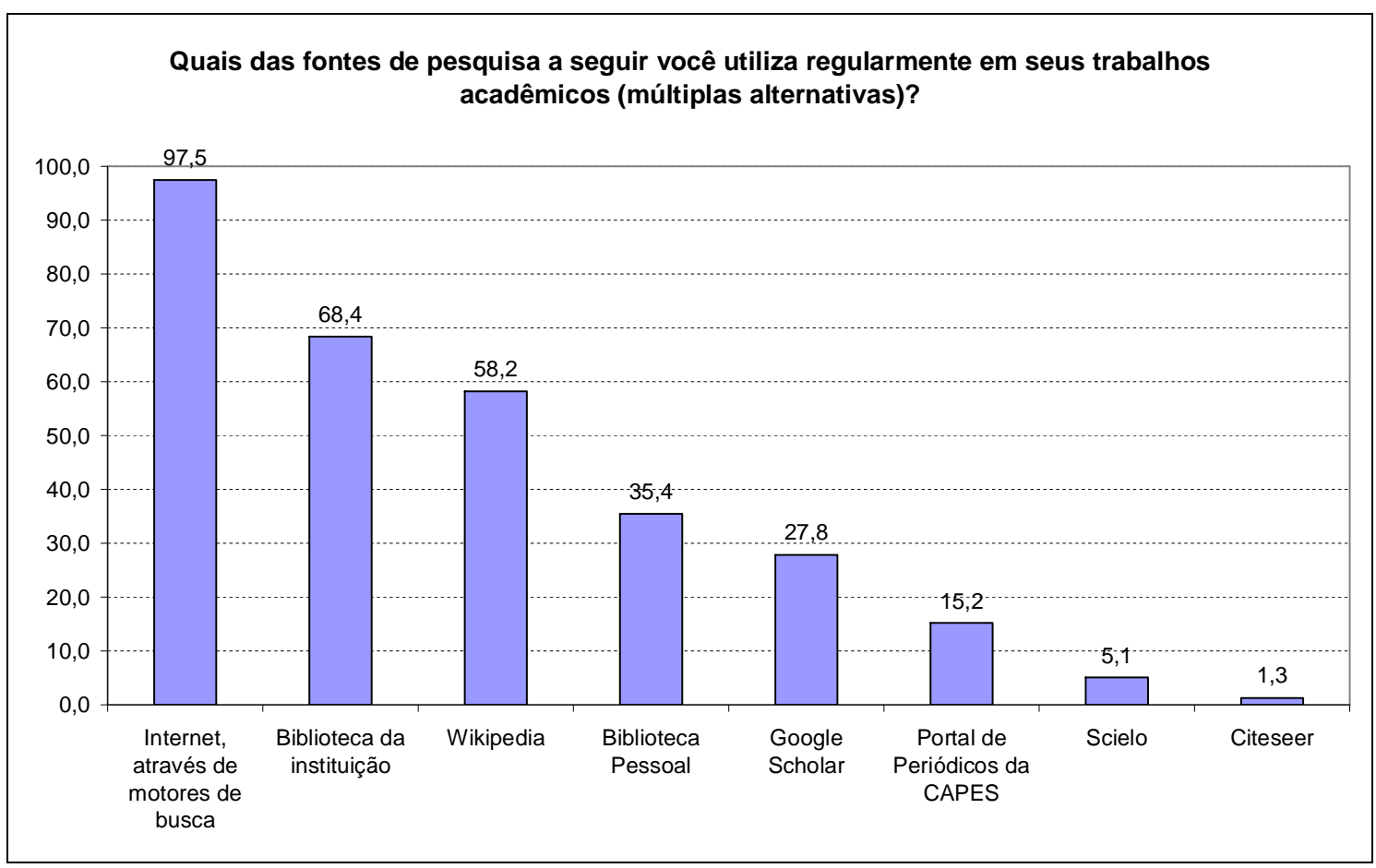

Figura 5 - Fontes de pesquisa indicadas

Em relação ao uso de imagens de sítios na Internet, o problema parece ser mais grave. Os alunos indicam que utilizam as imagens da Internet em seus trabalhos simplemente porque as mesmas são acessíveis de maneira gratuita como podemos ver na Figura 6. Enquanto em relação aos textos, ainda parece haver preocupação com as citações, no caso de imagens, tal preocupação não aparece. Além disso, verificou-se que a prática de solicitar autorização para reprodução de imagens não ocorre na amostra pesquisada. 


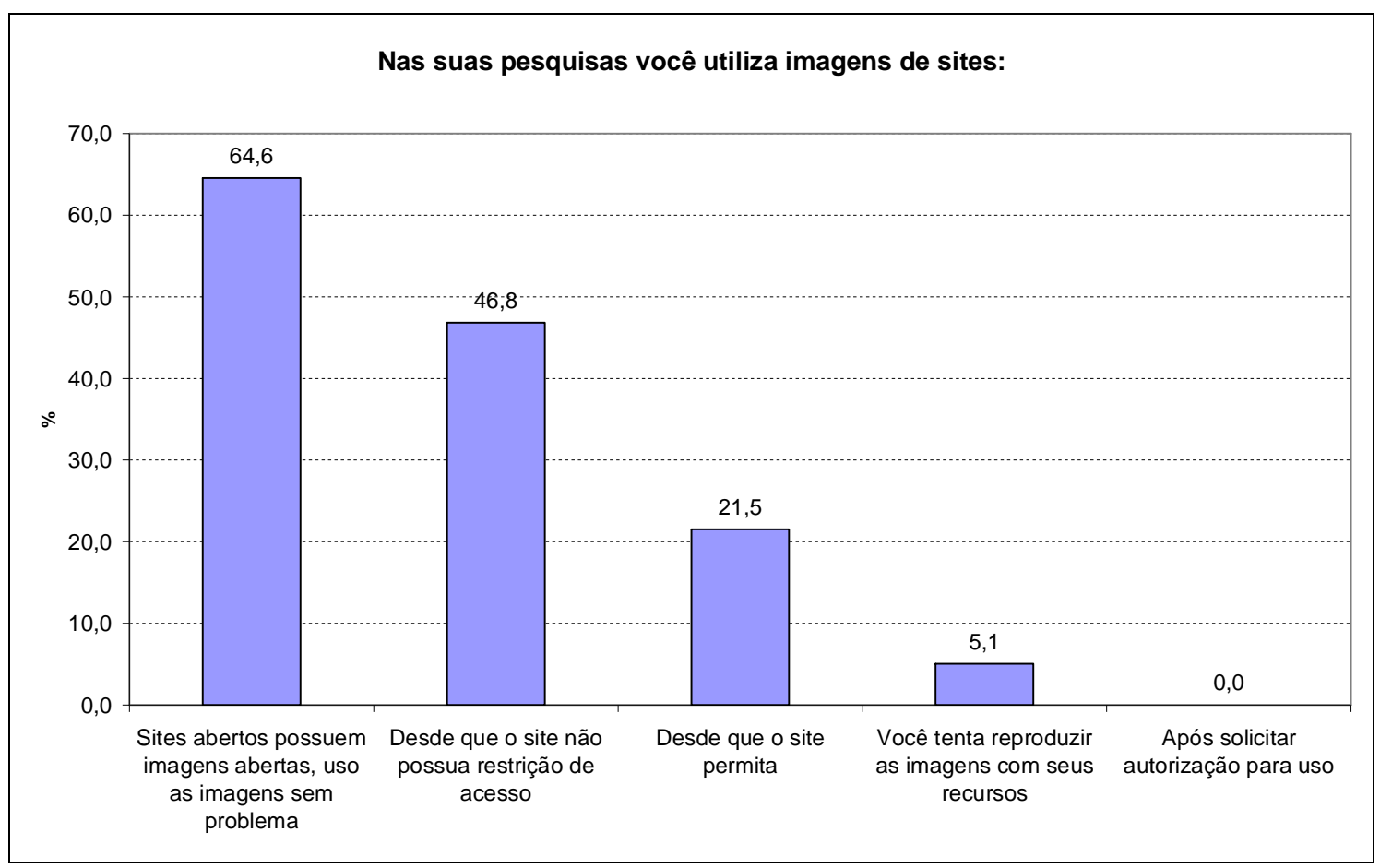

Figura 6 - Uso de imagens de sítios

Por fim, foi perguntado se os alunos tinham sido estimulados a colocar textos da Internet em trabalhos acadêmicos no Ensino Básico e se eles tinham recebido orientações sobre Direitos Autorais ao longo de sua formação, como podemos, respectivamente, ver nas Figuras 7 e 8. Verifica-se uma situação semelhante à descrita por Garschagen (2006), na qual uma das razões apontadas para o plágio acadêmico seja o estímulo ocorrido nos níveis fundamental e médio. Por outro lado, a falta de orientação sobre Direitos Autorais mostra a necessidade de inclusão da temática em disciplinas como Metodologia de Pesquisa. 
Florianópolis - SC - Brasil $\underline{\text { www.producaoonline.ufsc.br }}$

ISSN 1676 - 1901 / Edição especial/dezembro de 2007 Artigo selecionado dos anais - XXVII Encontro Nacional de Engenharia de Produção

\section{Nas suas pesquisas durante o ensino médio e/ou fundamental, você já foi estimulado} a utilizar textos da Internet e colocá-los em seus trabalhos?

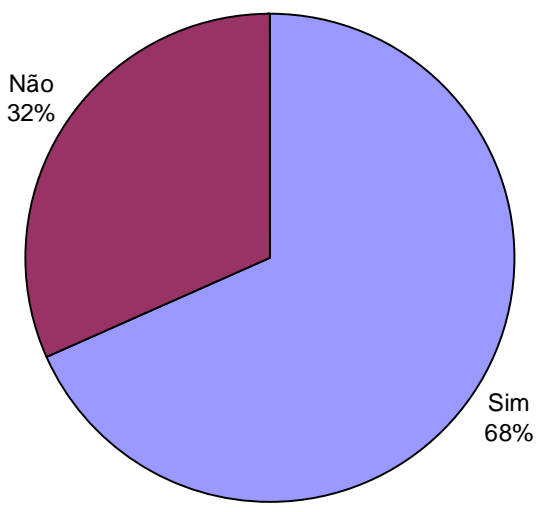

Figura 7 - Estímulo ao uso de material da Internet no Ensino Básico 


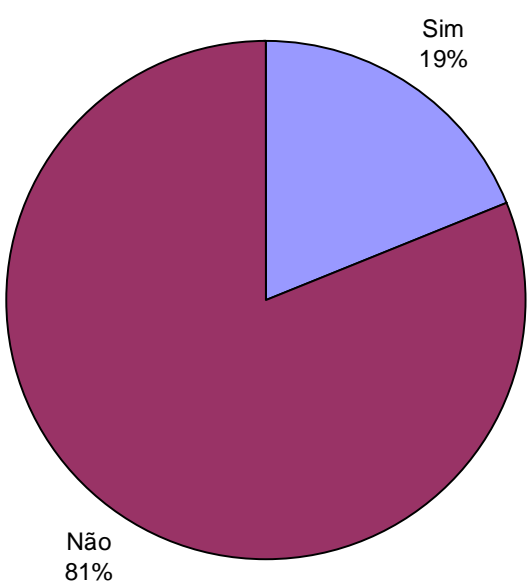

Figura 8 - Orientação sobre Direitos Autorais

\section{UMA PROPOSTA DE POLÍTICA DE COMBATE AO PLÁGIO ACADÊMICO}

A partir das respostas dos questionários, mostrou-se necessária a criação de uma política voltada ao combate do plágio acadêmico no âmbito do Curso de Engenharia de Produção do CEFET-RJ. Algumas medidas estão em processo de implantação:

- Divulgação de regras - Brown e Howell (2001) defendem que a divulgação de regras claras quanto às definições de plágio, bem como sobre a política universitária desencorajam os estudantes realizar práticas que violem o direito autoral. Austin e Brown (1999) dizem que a administração escolar deve assumir a responsabilidade de informar os alunos a respeito das violações de direito autoral. Está em estudos a 
inclusão da temática do Direito Autoral nas disciplinas Metodologia de Pesquisa e Projeto Final.

- Mudança de tipos de trabalho - Ao invés de se analisar apenas um trabalho final, podese estabelecer uma rotina de trabalhos intermediários, que possibilitem um acompanhamento mais próximo do aluno (Gibelman, 1999). Ao invés de se corrigir apenas uma versão final de uma monografia, professores devem exigir a realização de fichamentos, impressão de referências obtidas na WWW (quando permitido), transcrição de entrevistas e apresentações intermediárias. A oferta na Internet destes tipos de trabalho é muito reduzida, dificultando a fraude.

- Ferramentas de busca - As mesmas ferramentas de busca utilizadas para obtenção de trabalhos como o Google, também podem ser usadas para identificação do plágio. No tocante aos projetos finais, a comparação de trechos de trabalhos com sites através de motores de busca já é realizada de maneira informal. Pretende-se ampliar o uso de tais ferramentas entre os orientadores.

- Identificação de padrões de texto - A leitura atenta de determinados padrões ou variações em um texto podem revelar uma forte suspeita de plágio. Um texto, no qual um parágrafo possui construções sintáticas sofisticadas e outro simplórias pode ter sido copiado (Stebelman, 1998). Por outro lado, algumas mudanças abruptas no texto podem ser indicativos. Um texto narrativo, mudando para um texto que conversa com o leitor revela, no mínimo, que o autor demanda orientação quanto à redação. Da mesma forma, pode-se citar textos que mudam a redação, da terceira pessoa do singular para a primeira pessoa do plural. Outro indicativo típico que demanda confirmação é a utilização de referências no texto, não indicadas na bibliografia final. Pretende-se garantir maior tempo aos orientadores para uma leitura mais cautelosa dos trabalhos, extendendo-se o prazo de conclusão de Projetos Finais de um para dois semestres letivos.

\section{CONSIDERAÇÕES}

O problema do plágio acadêmico é hoje uma preocupação mundial. Foram apresentados os resultados de uma pesquisa junto aos alunos sobre seu conhecimento a 
respeito de Direitos Autorais, tendo sido elencados elementos de uma política para inibição da prática no âmbito do curso. Pretende-se ampliar a pesquisa, reproduzindo o questionário em outros níveis e instituições.

Verificou-se, com grande preocupação, o fato do plágio acadêmico ocorrer nos níveis Fundamental e Médio. Os alunos que aprendem a usar indevidamente as fontes na formação básica, poderão continuar a usá-las, indevidamente, durante educação superior e, futuramente, em trabalhos de pesquisa na pós-graduação.

A Internet é uma excepcional ferramenta que, ao mesmo tempo que facilita o plágio, também facilita a sua detecção. Por outro lado, o plágio só pode ser descoberto e coibido de fato se os professores dedicarem um tempo maior para a orientação e acompanhamento dos alunos nos seus trabalhos e houver uma maior conscientização de padrões éticos e legais por parte dos alunos. 


\section{REFERENCIAS}

AUSTIN, M.J.; BROWN, L.D. Internet Plagiarism: Developing Strategies to Curb Student Academic Dishonesty. Internet and Higher Education. Vol. 2, n.1, p. 21-33, 1999.

BILLIC-ZULLE, L. et al. Prevalence of Plagiarism among Medical Students. Croatian Medical Journal.. Vol. 46, n. 1, p. 126-131, 2005.

BROWN, V.J.; HOWELL, M.E. The Efficacy of Policy Statements on Plagiarism. Research in Higher Education. Vol. 42, n. 1, p. 103-118, 2001.

CARDOSO, C. C. Ethical Misconduct in the Business School: A Case of Plagiarism that Turned Bitter. Journal of Business Ethics. Vol. 49, p. 75-89, 2004.

CONNORS, M. Cybercheating the Internet could become the newest battleground in $\begin{array}{lllll}\text { academic } & \text { fraud } & 1996 . & \text { Disponível } & \text { em }\end{array}$ <http://www.carillon.uregina.ca/Sept12.96/feature/feature1.html> Acesso em 28/04/2007.

ECO, U. Como se faz uma tese. $11^{\text {a }}$ ed. Tradução de Guinsburg, J. São Paulo: Perspectiva, 1994.

GARSCHAGEN, B. Universidade em tempos de plágio. 2006. Disponível em: <http://observatorio.ultimosegundo.ig.com.br/artigos.asp?cod=366ASP006>. Acesso em 18/01/2007.

GRAHAM, L.; METAXAS, P.T. "Of course it's true; I saw it on the Internet!": Critical thinking in the Internet era. Communications of the ACM. Vol. 6 , n. 5, p. 70-75, 2003.

GIBELMAN, M.; GELMAN, S.R.; FAST, J. The downside of cyberspace: Cheating made easy. Journal of Social Work Education. Vol. 35, n. 3, p. 367-376, 1999. 
HARTMANN, E. Variações sobre plágio. Confraria - Arte e Literatura. n. 8, mai/jun 2006. Disponível em <http://acd.ufrj.br/ confrariadovento/numero8/ensaio03.htm> Acesso em 04/05/2007.

KOCK, N. A case of academic plagiarism. Communications of the ACM, Vol.42, n. 7, p. 96-104, 1999.

SCOFIELD Jr, G. China amplia punição para fraude acadêmica. O Globo. Domingo, 29 de abril de 2007, p. 32.

STEBELMAN, S. Cybercheating: dishonesty goes digital. American Libraries. Vol. 29, n. 8, p. 48-50, 1998.

WOOD, G. Academic Original Sin: Plagiarism, the Internet, and Librarians. Journal of Academic Librarianship. Vol. 30, n. 3, p. 237-242, 2004. 